\title{
Masking Level Difference and Electrophysiological Evaluation in Adults with Normal Hearing
}

\author{
Joyce Miranda Santiago $^{1}$ Cyntia Barbosa Laureano Luiz ${ }^{1} \quad$ Michele Garcia $^{2}$ Daniela Gil ${ }^{1}$ \\ ${ }^{1}$ Department of Speech Language Pathology, Escola Paulista de \\ Medicina, Universidade Federal de São Paulo, São Paulo, Brazil \\ 2 Department of Speech Language Pathology, universidade Federal de \\ Santa Maria, Santa Maria, RS, Brazil \\ Address for correspondence Joyce Miranda Santiago, Department of \\ Speech Language Pathology, Escola Paulista de Medicina, \\ Universidade Federal de São Paulo, Rua Botucatu, 802, Vila \\ Clementino, São Paulo, SP, 04023-062, Brazil \\ (e-mail: joyce.m.s07@gmail.com).
}

Int Arch Otorhinolaryngol 2020;24(4):e399-e406.

\begin{abstract}
Keywords

- auditory perception

- electrophysiology

- brainstem

- perceptual masking

- adult

Introduction The auditory structures of the brainstem are involved in binaural interaction, which contributes to sound location and auditory figure-background perception.

Objective To investigate the performance of young adults in the masking level difference (MLD) test, brainstem auditory-evoked potentials (BAEPs) with click stimulus, and frequency-following response (FFR), as well as to verify the correlation between the findings, considering the topographic origin of the components of these procedures.

Methods A total of 20 female subjects between 18 and 30 years of age, with normal hearing and no complaints concerning central auditory processing underwent a basic audiological evaluation, as well as the MLD test, BAEP and FFR.

Results The mean result on the MLD test was of $10.70 \mathrm{~dB}$. There was a statistically significant difference in the absolute latencies of waves I, III and V in the BAEPs of the ears. A change in the FFR characterized by the absence of the $C, E$ and $F$ waves was noticed. There was a statistically significant difference in the positive correlation of wave $V$ in the BAEPs with the MLD. There was a statistically significant difference in the positive correlation of the mean MLD and the $\mathrm{V}, \mathrm{A}$ and $\mathrm{F}$ components of the FFR.

Conclusion The mean MLD was adequate. In the BAEPs, we observed that the click stimulus transmission occurred faster in the right ear. The FFR showed absence of some components. The mean MLD correlated positively with the BAEPs and FFR.
\end{abstract}

\section{Introduction}

Central auditory processing (CAP) consists of a set of auditory abilities when the individual needs to interpret what he/she hears. ${ }^{1}$ It represents the efficiency and effectiveness of the central nervous system (CNS) in using auditory information. ${ }^{2}$ Central auditory processing involves a series of processes that encompass the peripheral and central auditory nervous system, and may involve non-auditory cortical areas such as the frontal lobe and the temporal-parietal-occipital connection. ${ }^{3,4}$

received

May 26, 2019

accepted

November 17, 2019 10.1055/s-0040-1701266. ISSN 1809-9777.
The auditory abilities involved in CAP include sound location, auditory closure, figure-background perception, binaural synthesis or integration, binaural separation, discrimination, memory and attention. ${ }^{5}$

Binaural interaction refers to the ability to process disparate but complementary information presented to both ears, that is, sequential information presented to each ear that together make up the complete message, requiring the integration of the two sets of information to provide the perception of the whole. ${ }^{6}$ This phenomenon occurs initially

Copyright $\odot 2020$ by Thieme Revinter Publicações Ltda, Rio de Janeiro, Brazil

License terms

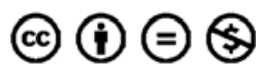


in the brainstem, and, subsequently, in the other structures of the CNS. The superior olivary complex is the first structure of the central auditory nervous system to receive ipsilateral and contralateral information (binaural station). The convergence of sound information originating in each ear attributes to the superior olivary complex a critical role in listening, which requires the integration and binaural interpretation of sound signals. ${ }^{7}$

Masking level difference (MLD) is a psychoacoustic test that determines the sensitivity of the auditory system for differences in time and signal amplitude and/or noise. The MLD test consists of the differentiation of detection or recognition of binaural conditions in which the signal or noise phase (masking) is manipulated. ${ }^{8}$ Literature findings indicate that the MLD corresponds to a behavioral measure of the effect of binaural interaction $^{9,10}$ that occurs at the brainstem level. ${ }^{11}$

Brainstem auditory-evoked potentials (BAEPs) are bioelectrical activities in response to auditory stimuli that occur between $0 \mathrm{~ms}$ and $10 \mathrm{~ms}$ after the presentation of the acoustic stimulus. ${ }^{12}$ The BAEPs are an electrophysiological measurement (thus, an objective measurement) generated by the synchronism of the structures of the auditory pathway, which begins in the auditory nerve, passing through the cochlear nucleus, the superior olivary complex, the lateral lemniscus, until the inferior colliculus. The most used acoustic stimulus is the click, which triggers a synchronic response of a large number of neurons and presents a wide spectrum of frequencies. The presence or absence of responses within a certain time (latency) enables the assessment of the integrity of the auditory pathway to the brainstem. ${ }^{13,14}$

Speech is a complex acoustic signal both in spectral and temporal resources. An essential function of the central auditory system is the neural coding of speech sounds. ${ }^{14}$

The authors of a recent research ${ }^{15}$ have explained that BAEP is an inadequate nomenclature, and the terminology that uses generators may be misleading, especially "S-BAEP" and the inappropriate term "Brainstem," because there is evidence that the frequency-following response (FFR) has not only cortical contribution, ${ }^{16}$ but also contribution of fibers of the eighth nerve. ${ }^{17}$ Thus, in the present study, the recommended terminology - frequency-following response - will be used to refer to the electrophysiological response generated by the presentation of speech stimulus.

The FFR generates brainstem responses that provide information about how the syllabic structure of the word is encoded by the auditory system. Thus, the FFR provides a mechanism to understand the neural basis for normal and altered auditory functions, generating an individual and quantifiable measurement of attention and neural coding for speech sounds. ${ }^{18}$

Thus, the FFR involves the participation of the brainstem, and of the subcortical and cortical structures, ${ }^{15,16,19-21}$ reflecting the response of various structures of the central auditory nervous system for speech sound processing.

It is noteworthy that there are few recent studies in the literature investigating the relationship between the MLD, the BAEP and the FFR. Thus, in view of the aforementioned evidences, the study of the results of the MLD and the BAEP with click stimulus and the FFR is necessary to investigate their correlation, because all procedures have the brainstem as their main source. Since the FFR is a new electrophysiology measurement in the clinical practice, it is important to demonstrate its results in conjunction with some traditional measurements of audiological diagnosis.

Thus, the objective of the present study is to investigate the performance of young adults in the MLD, the BAEP with click stimulus, and the FFR, as well as to verify the correlation between them, considering the topographic origin of the components of these procedures.

\section{Method}

The present is a descriptive, cross-sectional study. The work was conducted at the Central Auditory Processing and Electrophysiology Outpatient facility of a public university in Brazil. This research was approved by the institutional Ethics in Research Committee (under number 1168/2016 and CAAE 58978316.3.0000.5505). All participants were informed about the procedures to be performed and, after agreeing to participate in the research, they signed the informed consent form (ICF).

A total of 20 volunteers, all female (convenience sample), met the following inclusion criteria:

- Age between 18 and 30 years;

- Auditory thresholds within normal levels $(\leq 25 \mathrm{dBHL}$ between the frequencies of $250 \mathrm{kHz}$ and $8 \mathrm{kHz}$ );

- Type-A tympanograms (normal); and

- Dichotic digits test within normal range.

The exclusion criteria were as follows:

- Complaints regarding CAP;

- CAP disorders;

- Positive otological data for otitis media;

The material used in the present study were the results of the behavioral (MLD) and electrophysiological (BAEP with click stimulus and FFR) evaluations of hearing performed in the selected group.

The participants were first submitted to the MLD test, which was performed in an acoustic booth with supra-aural earphones. The participant was instructed to respond NO when she heard only the noise, and YES when she heard the noise and the whistle, even when in low intensity. In this version of the MLD test, 33 segments of narrowband noise were presented in 50 dBSL in 3 different conditions: SoNo (signal and homophasic noise in both ears), S $\pi$ No (antiphase signal in one ear and homophasic noise in both ears), and NT (noise without signal). The MLD was determined by the difference between the number of times the individual detected the presence of the signal under SoNo and S $\pi$ No conditions. Results $>10 \mathrm{~dB}$ were considered normal in this analysis, as proposed in the literature. ${ }^{22}$ The test was performed with a 2002 Auditec CD (Saint Louis, MO, US) played in a CD player coupled to the audiometer.

In the BAEP test with click stimulus and in the FFR, information was obtained concerning the electrophysiological 
activity of the auditory system in the brainstem, and of several structures of the Central Auditory Nervous System. The SmartEP(Intelligent Hearing Systems, Miami, FL, US) equipment was used. The surface of the skin was cleaned with hydrophilic gauze and abrasive paste. Then, surface electrodes were applied with electrolytic paste, to improve electrical conductivity, and microporous adhesive tape. The electrodes were positioned according to the international norms front $(\mathrm{Cz}$ : positive electrode; Fpz: ground electrode) in the lobes of the right and left ears (A2 and A1 - negative electrodes). The participant would sit in a reclining chair and was instructed to remain as relaxed as possible to avoid myogenic interference. In addition, the participants would watch a movie of their choice in the mute mode during the acquisition of the FFR. The electrophysiological records of the BAEP and FFR underwent an analysis of agreement between two evaluators. For these analyses, each evaluator received the obtained record of the BAEP and one record of the FFR without wave labeling. If the evaluators did not agree, a third evaluator would be recruited.

Rarefaction clicks were used in the BAEP, and they were presented monoaurally using insert earphones (Intelligent Hearing Systems, Miami, Florida, United States of America) at $80 \mathrm{dBnHL}$, at a presentation rate of 19.1 clicks per second, lasting $0.1 \mathrm{~ms}$, and totaling 2,048 stimuli. The recording window was of $12 \mathrm{~ms}$, and the gain of $100 \mathrm{~K}$ with high-pass filter was set at $100 \mathrm{~Hz}$, and the low-pass filter was set at $3,000 \mathrm{~Hz}$, with impedance below $5 \mathrm{k} \Omega$. The BAEP record was obtained with the individual sitting in a reclining chair in an acousticallytreated room. Two records for each side were taken, checking the reproduction of the plotted recordings to confirm the responses. In the plotted recordings, waves I, III and V and interpeaks I-III, III-V and I-V were analyzed for latency, which enabled the evaluation of the integrity of the auditory pathway. The interaural difference of the absolute latency of wave $V$ was also analyzed. The criterion of normality for the analysis of this evaluation was the one proposed by the biological standardization of the equipment, presented in - Box 1.

In the FFR, the acoustic stimulus used was the synthesized syllable /da/ with alternating polarity and duration of $40 \mathrm{~ms}$, presented monoaurally to the right ear at $80 \mathrm{dBnHL}$, at a presentation rate of 10.9 stimuli per second. The recording

Box 1 Normative BAEP values for clicks at $80 \mathrm{dBnNA}$ proposed by the biological standardization of the Intelligent Hearing Systems equipment

\begin{tabular}{|l|l|l|}
\hline $\begin{array}{l}\text { Waves and } \\
\text { interpeaks }\end{array}$ & $\begin{array}{l}\text { Mean values of the } \\
\text { absolute latency (ms) }\end{array}$ & Standard deviation \\
\hline I & 1.65 & 0.06 \\
\hline III & 3.80 & 0.15 \\
\hline V & 5.67 & 0.16 \\
\hline I-III & 2.15 & 0.16 \\
\hline III-V & 1.86 & 0.12 \\
\hline I-V & 4.01 & 0.17 \\
\hline
\end{tabular}

Abbreviations: BAEP, brainstem auditory-evoked potentials; dBnNA, decibel normal hearing level; ms, milliseconds. window was of $60 \mathrm{~ms}$, the gain of $150 \mathrm{~K}$ with the high-pass filter was set at $50 \mathrm{~Hz}$, and the low-pass filter, at 3,000 Hz. A total of 2 scans of 3,000 stimuli were performed, and the number of artifacts was always $<10 \%$ of the total stimuli presented in each scan. After the reproduction of the waves, the obtained plots were added in a weighted fashion, and the high-pass spectral filter of $100 \mathrm{~Hz}$ and the low-pass filter of $2,000 \mathrm{~Hz}$ were applied to the resulting plot, and then the onset response components ( $\mathrm{V}$ and $\mathrm{A}$ ) and the $\mathrm{C}, \mathrm{D}, \mathrm{E}, \mathrm{F}$ and $\mathrm{O}$ components were identified and analyzed for complex V-A. latency and amplitude. The identification of the components was based on the metric waveform model of the Navigator Pro (Natus Medical, Inc., Schaumburg, IL, US) equipment.

For the statistical analysis, the Wilcoxon nonparametric test was used because the dataset had a low sample $(<30$ participants). Thus, the central limit theorem does not guarantee that the distribution will tend to a normal distribution, which is the basic assumption for the use of parametric techniques. ${ }^{23,24}$ Thus, the Wilcoxon test was used to evaluate data produced in the BAEP with click stimulus and in the MLD. The Spearman correlation index was used to report the degree of association between two variables. ${ }^{23}$ This index was used to analyze the correlation between the mean MLD with the BAEP with click stimulus, and of the mean MLD with the FFR.

The correlation test, in which the correlation coefficient is used as in the case of mean and variance, was also used to test this correlation coefficient between two variables. ${ }^{25}$ The correlation test was applied to the correlation between the mean MLD data with the BAEP with click stimulus and the mean MLD with the FFR.

The confidence interval $(\mathrm{CI})$ for the mean is a technique that has been used to investigate the extent to which the mean can vary in a given confidence probability. ${ }^{23}$ The data of the mean MLD, BAEP with click stimulus and FFR were analyzed by the CIs.

The level of significance adopted in the present study was of 0.05 (5\%). ${ }^{23,24,26,27}$ The $p$-value was analyzed in the results of the BAEP with click stimulus.

\section{Results}

A total of 20 female subjects were evaluated. The mean age of the total sample was 25.1 years old (standard deviation [SD]: 3.57), characterizing a sample of young adults.

- Table 1 shows the results of the MLD test, with means, medians, standard deviations, numbers and confidence intervals.

- Table 2 shows the descriptive measures of the latencies of waves I, III, V, and interpeak intervals I-III, III-V, I-V of the

Table 1 Descriptive measures of the mean of the results of the masking level difference $500 \mathrm{~Hz}$ test

\begin{tabular}{|l|l|l|l|l|l|}
\hline $\begin{array}{l}\text { MLD } \\
500 \mathrm{~Hz}\end{array}$ & $\begin{array}{l}\text { Mean } \\
(\mathrm{dB})\end{array}$ & Median & $\begin{array}{l}\text { Standard } \\
\text { deviation }\end{array}$ & $\mathrm{N}$ & $\mathrm{Cl}$ \\
\cline { 2 - 6 } & 10.70 & 10.00 & 3.74 & 20 & 1.64 \\
\hline
\end{tabular}

Abbreviations: $\mathrm{Cl}$, confidence interval; $\mathrm{dB}$, decibel; $\mathrm{Hz}$, hertz; MLD, masking level difference; $\mathrm{N}$, number. 
Table 2 Absolute latencies of waves I, III, V and interpeaks I-III, III-V, IV of the BAEP with click stimulus of the right and left ears

\begin{tabular}{|c|c|c|c|c|c|c|c|}
\hline BAEP with click stimulus & Ear & Mean (ms) & Median & Standard deviation & $\mathrm{N}$ & $\mathrm{Cl}$ & $p$-value \\
\hline \multirow[t]{2}{*}{ Wave I } & Right & 1.66 & 1.65 & 0.08 & 20 & 0.04 & \multirow[t]{2}{*}{$<0.001$} \\
\hline & Left & 1.76 & 1.78 & 0.09 & 20 & 0.04 & \\
\hline \multirow[t]{2}{*}{ Wave III } & Right & 3.83 & 3.83 & 0.12 & 20 & 0.05 & \multirow[t]{2}{*}{$0.004^{*}$} \\
\hline & Left & 3.93 & 3.94 & 0.18 & 20 & 0.08 & \\
\hline \multirow[t]{2}{*}{ Wave V } & Right & 5.65 & 5.64 & 0.11 & 20 & 0.05 & \multirow[t]{2}{*}{$0.003^{*}$} \\
\hline & Left & 5.76 & 5.72 & 0.14 & 20 & 0.06 & \\
\hline \multirow[t]{2}{*}{ Interpeak I - III } & Right & 2.17 & 2.18 & 0.11 & 20 & 0.05 & \multirow[t]{2}{*}{0.962} \\
\hline & Left & 2.17 & 2.20 & 0.13 & 20 & 0.06 & \\
\hline \multirow[t]{2}{*}{ Interpeak III-V } & Right & 1.82 & 1.79 & 0.14 & 20 & 0.06 & \multirow[t]{2}{*}{0.758} \\
\hline & Left & 1.83 & 1.84 & 0.14 & 20 & 0.06 & \\
\hline \multirow[t]{2}{*}{ Interpeak I - V } & Right & 3.99 & 3.98 & 0.11 & 20 & 0.05 & \multirow[t]{2}{*}{0.936} \\
\hline & Left & 4.00 & 3.98 & 0.14 & 20 & 0.06 & \\
\hline
\end{tabular}

Abbreviations: BAEP, brainstem auditory-evoked potentials; $\mathrm{Cl}$, confidence interval; ms, milliseconds; $\mathrm{N}$, number.

Note: ${ }^{*} p$-value considered statistically significant.

BAEP with click stimulus, presenting the means, medians, SDs, numbers, confidence intervals and $p$-values, considering the ears separately, as well as the comparison between them.

It is evident in $\mathbf{- T a b l e ~} 2$ that there was a statistically significant difference in the absolute latencies when the right and left ears were compared. We observed that the left ear presented higher absolute latency values than those of the right ear for waves I, III and V.

- Table 3 shows the descriptive statistics of the amplitude results of the V-A complex and the results of the absolute latencies of the $V, A, C, D, E, F$ and $O$ waves of the FFR obtained in the right ear.

We observed in $\boldsymbol{\sim}$ Table 3 that the sample for the C, E and F waves was smaller because in seven individuals wave $C$ was absent, four individuals had no wave $\mathrm{E}$, and one individual had absence of the $\mathrm{F}$ wave. Regarding the amplitude of the $\mathrm{V}$ A complex, an adequate value was observed.

-Figure 1 shows the correlation between the mean MLD and the BAEP with click stimulus, and - Figure $\mathbf{2}$ shows the correlation between the mean MLD and the FFR.
-Figure 1 indicates that there was a statistically significant difference in the correlation between the $\mathrm{V}$ wave of the BAEP with click stimulus and the mean MLD, and this correlation was positive and classified as regular.

As shown in - Figure 2, there was a statistically significant difference in the correlation between the mean MLD with the following components of the FFR: V, A and F. The correlation between the mean MLD and waves V, A and F of the FFR was positive. It is worth mentioning that the classification of the correlation between the MLD and the A and V waves was regular, and the classification of the correlation between the mean MLD and the F wave was classified as good.

\section{Discussion}

Binaural interaction contributes to sound location and auditory figure-background perception. ${ }^{6}$ The brainstem is responsible for detecting differences in time and intensity between the ears, ${ }^{28}$ contributing to speech recognition in the presence of competitive auditory information, resulting in better detection of sound in noisy environments. In light of

Table 3 Descriptive statistics of the amplitude of the V-A complex and the latency of the V, A, C, D, E, F and O waves of the FFR obtained in the right ear

\begin{tabular}{|l|l|l|l|l|l|}
\hline FRR & Mean $(\mu \mathrm{V}$ and $\mathrm{ms})$ & Median & Standard deviation & $\mathrm{N}$ & $\mathrm{Cl}$ \\
\hline Amplitude of the V-A complex & 0.30 & 0.29 & 0.08 & 20 & 0.04 \\
\hline Wave V & 6.87 & 6.88 & 0.44 & 20 & 0.19 \\
\hline Wave A & 8.16 & 8.00 & 0.49 & 20 & 0.22 \\
\hline Wave C & 17.88 & 17.88 & 0.84 & 13 & 0.46 \\
\hline Wave D & 23.20 & 23.00 & 0.57 & 20 & 0.25 \\
\hline Wave E & 31.88 & 31.75 & 0.71 & 16 & 0.35 \\
\hline Wave F & 40.23 & 40.25 & 0.77 & 19 & 0.35 \\
\hline Wave O & 48.39 & 48.25 & 0.27 & 20 & 0.12 \\
\hline
\end{tabular}

Abbreviations: $\mathrm{Cl}$, confidence interval; FFR, frequency-following response; ms, milliseconds; $\mathrm{N}$, number; $\mu \mathrm{V}$, microvolts. 


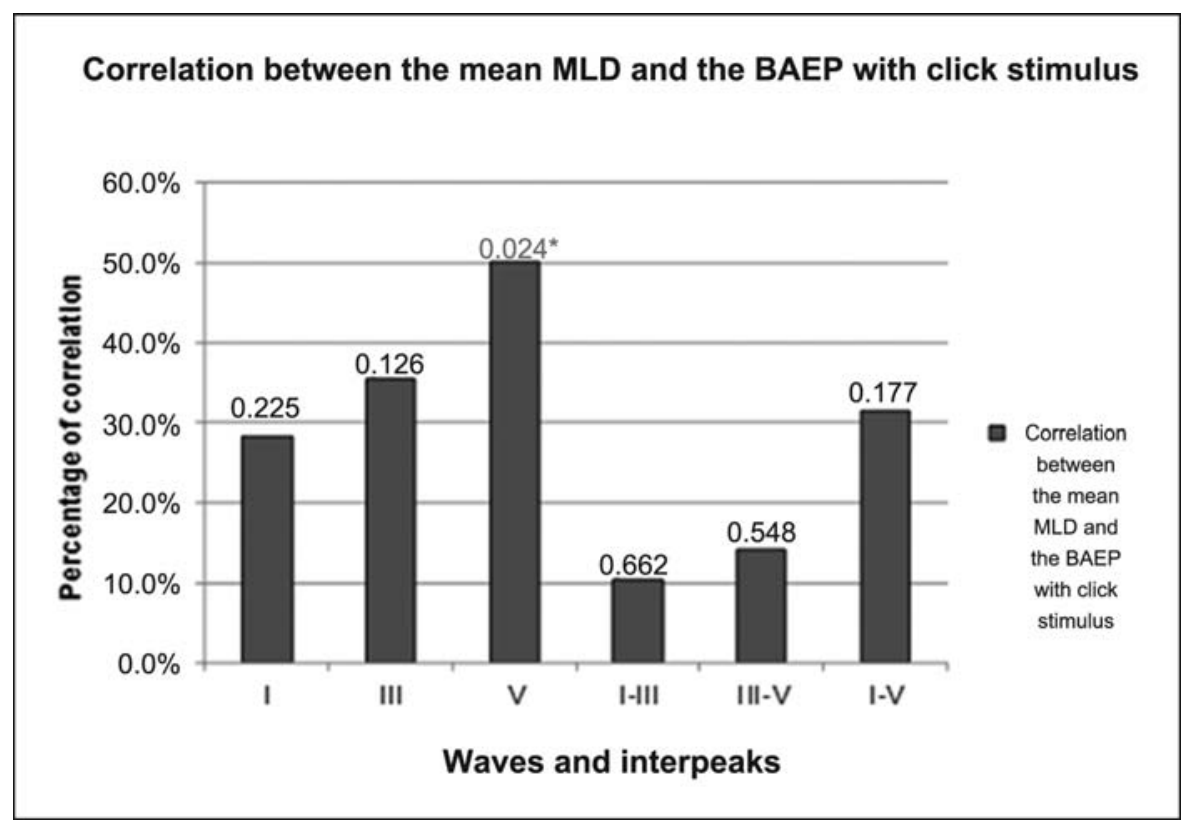

Figure 1 Correlation between the mean MLD and the BAEP with click stimulus. Abbreviations: MLD, masking level difference; BAEP, brainstem auditory-evoked potentials.

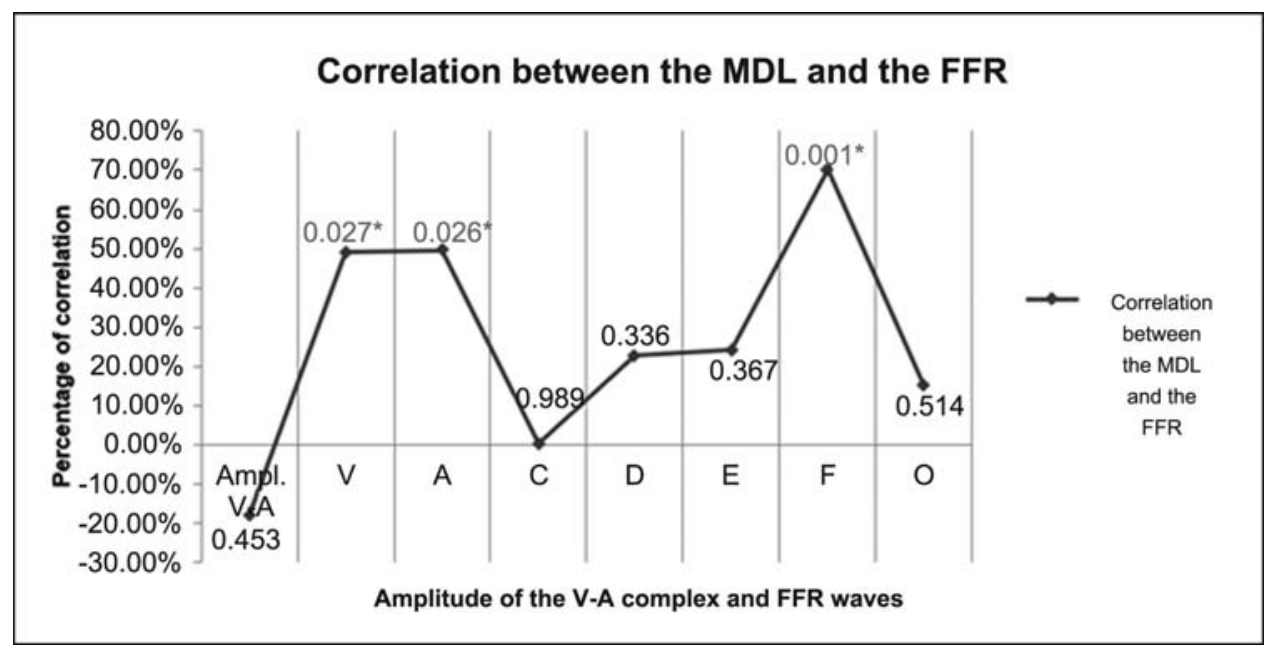

Figure 2 Correlation between the MLD and the FFR. Abbreviations: MLD, masking level difference; FFR, frequency-following response.

the aforementioned findings, the present study consisted of an investigation of the performance of individuals using the following procedures involving the brainstem structure: the MLD, the BAEP with click stimulus, and the FFR. It also aimed at verifying the correlation between these measures, considering their topographic origin.

It was evidenced that the sample presented a mean MLD response of $10.70 \mathrm{~dB}$ and a median of $10 \mathrm{~dB}$, which is in line with the findings in the literature that validated the MLD protocol for $500 \mathrm{~Hz}$ tones to be implemented for clinical evaluation in a simple and reliable way, and which adopted the normality criterion with the MLD value $\geq 10 \mathrm{~dB}$ for adult listeners with normal pure tone thresholds, ${ }^{22}$ as shown in -Table 1. Thus, the results of the mean MLD showed that the population of the present study presented adequate binaural integration ability, evaluated by a behavioral method.
There was a statistically significant difference between the absolute latencies of waves I, III, and V considering the right and left ears (-Table 2). We observed that the absolute latencies of the left ear were greater than those of the right ear. It can be inferred that there was a difference in the processing speed of the click stimulus between the ears, suggesting that the time of transmission of the click stimulus occurred faster in the right than in the left ear. These results disagreed with the findings in the literature that showed no significant differences when the right and left ears were compared, ${ }^{29-31}$ especially in individuals with normal auditory thresholds and no complaints. Furthermore, the literature findings showed that in individuals with normal peripheral hearing, the responses of the two ears in the BAEP with click stimuli were similar, because the anatomical structures involved consist of the brainstem, that is, they are the same structures used by both ears when sound stimulation occurs. ${ }^{29}$ 
Some individuals presented absence of waves $\mathrm{C}, \mathrm{E}$ and $\mathrm{F}$ in the FFR. We also observed that the V-A complex presented normal amplitude values using the metric model of normative wave of the Navigator Pro equipment. We also observed that the mean values of the V, A, C, D, E, and F latencies were similar to the normative values, and, in the present study, the mean of the latencies were found to be slightly increased (-Table 3). This can be explained by small differences in the procedures for collecting and analyzing responses, such as electrode positioning. In the FFR, the $\mathrm{V}$ and $\mathrm{A}$ peaks are probably originated from the rostral brainstem (lateral lemniscus or inferior colliculus) and correspond to the onset of the speech signal. Peak $C$ possibly reflects the onset of loudness; the $\mathrm{D}, \mathrm{E}$ and $\mathrm{F}$ peaks are equivalent to the fundamental frequency $\left(\mathrm{F}_{0}\right)$ of the sound source. In turn, the $O$ peak consists of the speech sound offset, and reflects the end of the sound. ${ }^{19}$ The amplitude of the V-A complex represents the synchrony of the electrophysiological activity. ${ }^{32}$

The aforementioned findings of the present study, therefore, suggest that some individuals presented alteration in the processing for the speech sound at the beginning of the sonority and fundamental frequency of the stimulus.

The literature pointed out that the FFR was more sensitive for the evaluation of the CAP, indicating possible alterations in the synchrony and speed of neural impulses in the speech processing, mainly regarding the linguistic information of such impulses. ${ }^{33}$ Furthermore, recent studies have shown that there is a probability of $85.15 \%$ of subjects with altered FFR to present Central Auditory Processing Disorder. ${ }^{34}$ It is noteworthy that an earlier study demonstrated that, in some individuals, the $C$ wave does not appear as a stable component. ${ }^{35}$ Therefore, the absence of components in the present study should be analyzed along with the behavioral evaluation of auditory processing, especially in procedures involving temporal processing, which correlate to paralinguistic aspects of speech.

As observed in - Figure 1, wave V of the BAEP click stimulus correlated positively with the mean MLD, that is, the greater the absolute $\mathrm{V}$ wave latency, the higher the mean MLD value. These findings disagreed with that of the study that indicated a correspondence between the MLD and the presence of alterations in wave III of the BAEP with click stimulus. ${ }^{36}$ In addition, a literature review ${ }^{37}$ concluded that when the latency and/or amplitude of wave III of the BAEP with click stimulus is compromised, the MLD would also be altered, which is different from the findings of the present study, in which an increased absolute latency of wave III in the left ear and MLD results within normal limits were demonstrated.

Thus, in view of the findings of the present study and of the aforementioned literature, it is inferred that the inferior colliculus may also play an important role in binaural interaction. ${ }^{38}$ Therefore, this may suggest that the BAEP with click stimulus and the MLD can share the same brainstem structures. $^{36,39}$ Thus, the results of the present study make it possible to infer that when the processing time of the stimulus of the lateral lemniscus and lower colliculus is higher (involvement of the $\mathrm{V}$ wave), a higher MLD threshold will also be obtained. Thus, the findings of the present research suggest that when the individual has a longer latency of wave $V$, the average MLD may be normal, suggesting that the binaural interaction would be adequate, and that the dysfunction in the nervous transmission would be restricted to sites generating a high brainstem response.

The mean MLD correlated positively with waves $\mathrm{V}$, A and $\mathrm{F}$ of the FFR; in other words, the higher the mean MLD, the higher the absolute latencies of the $\mathrm{V}, \mathrm{A}$ and $\mathrm{F}$ waves, which goes against what would be expected for the present study (-Figure 2). It is noteworthy that no studies correlating the mean MLD with the FFR were found in the literature. Due to the absence of specific literature, our findings were compared with those of other studies that defined the anatomy and physiology of both procedures involved in the present study. The FFR receives a strong contribution from the synchronous activity of the inferior colliculus. ${ }^{15,16,19-21}$ As previously mentioned, the inferior colliculus seems to play an important role in the sound location of the binaural process. ${ }^{38}$ However, the literature showed that the FRR also arises from the synchronous activity at the lateral lemniscal level; ${ }^{20,21}$ the auditory cortex has a strong influence on the fundamental frequency of the stimulus, as well as the signal coming from the cochlear nucleus, inferior colliculus and medial geniculate body, ${ }^{16}$ and the synchronic activity has a strong contribution in the mesencephalon..$^{15}$ The brainstem aids in the speech recognition in the presence of competitive auditory information, which contributes to the detection of sound in noisy environments. ${ }^{11}$

The results of the present study showed that the longer the processing time of the stimulus in the onset of speech ( $\mathrm{V}$ and $\mathrm{A}$ waves) and in the final component of the FFR ( $F$ wave), the greater the mean MLD. Thus, if the $\mathrm{V}, \mathrm{A}$ and $\mathrm{F}$ waves of the FFR are compromised, the mean MLD will not be compromised.

The perception of difference in the masking level through temporal cues and changes in the stimulus phase also require binaural interaction, and both occur in the superior olivary complex. ${ }^{9}$ The cochlear nucleus relates to temporal processing for sound location by identifying interaural time differences, aiding in the analysis of complex signals and suppressing background noise, ${ }^{38}$ thus contributing to binaural interaction. The cochlear nucleus, the trapezoid body and the superior olivary complex contribute to the formation of wave III; the lateral lemniscus and inferior colliculus originate the $V$ wave of the BAEP with click stimulus. ${ }^{40,41}$ The FFR reflects the synchronic activity of the cochlear nucleus, lateral lemniscus, inferior colliculus, medial geniculate body, mesencephalon, and auditory cortex. . $^{15,16,20,21}$

Although the mean MLD and BAEP with click stimulus and FFR supposedly evaluated brainstem structures that contribute to binaural integration, the results were not found to be coincident. A difference between the results obtained in the BAEP with click stimulus and the FFR is expected because the stimuli are different and reflect neural processes that occur separately for the coding of the different signals (click and speech). ${ }^{42}$ Furthermore, aspects that reflect the change in the FFR are not evaluated in the MLD. In this perspective, when the electrophysiological evaluation was altered, the behavioral evaluation was supposed to be normal; this, however, did not happen in the sample evaluated in the present study. 
The major limitation of the present study concerns the record of the FFR and the protocol of analysis, which is still under validation. Some items were revised recently, when the current research was already under analysis. Moreover, the sites generating the FFR components have not yet been defined, which makes it difficult to discuss and generalize the findings. There is a need for further studies with larger samples and involving individuals with known neurological lesions to investigate other possible clinical correlations. Despite these limitations, the present study contributes to the clinical practice, since its results demonstrated that behavioral and electrophysiological measurements are complementary in the audiological diagnosis.

\section{Conclusion}

The mean MLD was adequate in the group of individuals studied. There was a difference in the processing speed of the BAEP with click stimulus between the ears; in the right ear, the transmission time of the click stimulus was faster than in the left ear. The FFR presented alterations mainly characterized by the absence of components.

The mean MLD correlated with the BAEP with click stimulus and the FFR; the higher the latencies of the V, A and $\mathrm{F}$ waves of the FFR, the greater the MLD.

\section{Conflict of Interests}

The authors have none to declare.

\section{References}

1 Katz J. Tratado de Audiologia Clínica. 4 ed. São Paulo: Manole; 1999:349-371

2 American Speech-Language-Hearing Association. (Central) Auditory Processing Disorders. Working Group on Auditory Processing Disorders; 2005:1-19

3 Musiek FE, Baran JA, Pinheiro ML. Behavioral and Electrophysiological Test Procedures. In: Musiek FE, Baran JA, Pinheiro ML. Neuroaudiology - Case Studies. San Diego, CA: Singular Publishing Group; 1994

4 Kandel ER, Schwartz JH, Jessel TM. Essentials of Neural Science and Behavior. New Jersey: Englewood Cliffs/Prentice Hall; 1995

5 Ferre JM. Processing power: a guide to Central Auditory Processing Disorder assessment and management. San Antonio, TX: Comunication Skill Builders; 1997

6 Bellis TJ. Assessment and management of Central Auditory Processing Disorders: from science to practice. San Diego: Singular Publishing Group; 1996

7 Bamiou DE. Measures of binaural interaction. In: Musiek FE, Chermak GD, editors. Handbook of Central Auditory Processing Disorder. Auditory Neuroscience and Diagnosis. San Diego, CA: Plural Publishing; 2007:1:257-286

8 Tobin H. Binaural interaction tasks. In: Pinheiro ML, Musiek FE, editors. Assessment of central auditory dysfunction: Foundations and clinical correlates. Baltimore: Williams and Wilkins; 1985:155-172

9 Durlach NI. Equalization and cancellation theory of binaural masking-level differences. J Acoust Soc Am 1963;35(08):1206-1218

10 McFadden D. Masking and the binaural system. In: Tower DB. editor. The nervous system, human communication and its disorders. New York: Raven Press; 1975

11 Goldstein DPE, Stephens SDG. Masking level difference: a measure of auditory processing capability. Audiology 1975;14(04): 354-367
12 Picton TW, Hillyard SA, Krausz HI, Galambos R. Human auditory evoked potentials. I. Evaluation of components. Electroencephalogr Clin Neurophysiol 1974;36(02):179-190

13 Matas CG. [Electrophysiological measures of hearing: Brainstem Auditory Evoked Potentials]. In: Carvalho RM. Fonoaudiologia: informação para a formação - procedimentos em audiologia. Rio de Janeiro: Guanabara Koogan; 2003:43-57

14 Abrams D, Kraus N. Auditory pathway representation of speech sounds in humans. In: Handbook of Clinical Audiology. Katz J, Hood L, Burkard R, Medwetsky L; 6th ed.: Lippincott Williams \& Wilkins; 2009:611-626

15 Kraus N, Anderson S, White-Schwoch T. The Frequency-Following Response: A Window into Human Communication. In: Kraus N, Anderson S, White-Scwoch T, Fay RR, Popper AN, editors. The Frequency-Following Response - A Window into Human Communication. Springer Handbook of Auditory Research; 2017,62; 1-15

16 Coffey EB, Herholz SC, Chepesiuk AM, Baillet S, Zatorre RJ. Cortical contributions to the auditory frequency-following response revealed by MEG. Nat Commun 2016;7:11070. Doi: 10.1038/ ncomms 11070

17 Shinn-Cunningham B, Varghese L, Wang L, Bharadwaj H. Individual Differences in Temporal Perception and Their Implications for Everyday Listening. In: Kraus N, Anderson S, White-Scwoch T, Fay RR, Popper AN, editors. The Frequency-Following Response - A Window into Human Communication. Springer Handbook of Auditory Research; 2017,62; 159-192

18 Russo N, Nicol T, Musacchia G, Kraus N. Brainstem responses to speech syllables. Clin Neurophysiol 2004;115(09):2021-2030. Doi: 10.1016/j.clinph.2004.04.003

19 Kraus N, Banai K. Listening, Literacy and the Neural Transcription of Sound. In DeConde Johnson C, Lewis DE, Mülder HE, Thibodeau LM, editors, Proceedings of the First International Virtual Conference on FM: Achieving Clear Communication, Employing Sound Solutions. Phonak Communictions AG. 2010:9-26

20 Krishnan A. Human Frequency-Following response. In: Burkard RF, Don M, Eggermont JJ, editors. Auditory evoked potentials: Basic principles and clinical application. Baltimore: Lippincott Williams \& Wilkins; 2007:313-335

21 Chandrasekaran B, Kraus N. The scalp-recorded brainstem response to speech: neural origins and plasticity. Psychophysiology 2010;47(02):236-246. Doi: 10.1111/j.1469-8986.2009.00928.x

22 Wilson RH, Moncrieff DW, Townsend EA, Pillion AL. Development of a $500-\mathrm{Hz}$ masking-level difference protocol for clinic use. J Am Acad Audiol 2003;14(01):1-8

23 Maroco J. Análise estatística com utilização do SPSS. $2^{\text {a }}$ ed. Lisboa: Lisboa, Sílabo; 2003

24 Conover WU. Pratical nonparametric statistics. 1st ed. Statistics New York: Jonh Willy \& Sons; 1971

25 Vieira S. Bio Estatística Tópicos Avançados, $2^{\text {a }}$ ed. Rio de Janeiro: Campus; 2004

26 Vieira S. Introdução à bioestatística. $3^{\mathrm{a}}$ ed. Rio de Janeiro: Campus; 1991

27 Barreiro-Branco FCA, Momensohn-Santos TM. [Evaluation and speech therapy in (Central) auditory processing disorders]. Fernandes FDM, Mendes BCA, Navas A, Pereira GP. Tratado de Fonoaudiologia. $2^{\mathrm{a}}$ ed. São Paulo: Roca; 2009:232-238

28 Carvallo RMM. [Auditory Process: basic audiological evaluation]. In: Pereira LD, Schochat E. Processamento auditivo central: manual de avaliação. São Paulo: Lovise; 1997:27-35

29 Esteves MCBN, Dell' Aringa AHB, Arruda GV, Dell' Aringa AR, Nardi JC. Brainstem evoked response audiometry in normal hearing subjects. Rev Bras Otorrinolaringol (Engl Ed) 2009;75(03):420-425. Available from: http://www.scielo.br/scielo.php?script=sci_arttext\&pid=S180 8-86942009000300018\&lng=enhttp://dx.doi.org/10.1590/S1808-86 942009000300018

30 Magliaro FCL, Scheuer CI, Assumpção Júnior FB, Matas CG. Estudo dos potenciais evocados auditivos em autismo. Pró-Fono R. Atual Cient. 2010;22(01):31-36. Available from: http://www.scielo.br/scielo. 
406 Masking Level Difference and Electrophysiological Evaluation Santiago et al.

php?script=sci_arttext\&pid=S0104-56872010000100007\&lng=en http://dx.doi.org/10.1590/S0104-56872010000100007

31 Magliaro FCL, Matas SLA, Matas CG. Potencial Cognitivo P300 em pacientes com lesão isquêmica do hemisfério direito. Pró-Fono $\mathrm{R}$. Atual. Cient 2009;21(04):285-290. Available from: http://www. scielo.br/scielo.php?script=sci_arttext\&pid=S0104-568720090004 00004\&lng=enhttp://dx.doi.org/10.1590/S0104-56872009000400 004

32 Wible B, Nicol T, Kraus N. Atypical brainstem representation of onset and formant structure of speech sounds in children with language-based learning problems. Biol Psychol 2004;67(03): 299-317

33 Filippini R, Schochat E. Brainstem evoked auditory potentials with speech stimulus in the auditory processing disorder. Braz. J. Otorhinolaryngol. (Impr.) 2009;75(03):449-455. Available from: http://www.scielo.br/scielo.php?script=sci_arttext\&pid=S1808869 42009000300022\&lng=enhttp://dx.doi.org/10.1590/S1808-86942 009000300022

34 Rocha-Muniz CN, Filippini R, Neves-Lobo IF, et al. Can speech-evoked Auditory Brainstem Response become a useful tool in clinical practice? CoDAS 2016;28(01):77-80http://www.scielo.br/scielo. php?script=sci_arttext\&pid=S231717822016000100077\&lng=en cited2019May11 10.1590/2317-1782/20162014231 [Internet]
35 Banai K, Hornickel J, Skoe E, Nicol T, Zecker S, Kraus N. Reading and subcortical auditory function. Cereb Cortex 2009;19(11):2699-2707. Doi: $10.1093 /$ cercor/bhp024

36 Noffsinger D, Olsen W, Carhart R, Hart C. Auditory and vestibular aberrations in multiple sclerosis. Acta Otolaryngol Suppl 1972; 303:1-63

37 Jerger J, Hannley M, Rivera V. Auditory Brainstem Response and the Masking Level Difference. Ann N Y Acad. Science 1982; ...:466-470

38 Teixeira CF, Griz SMS. [Central hearing system]. In: Bevilacqua MC org. Tratado de Audiologia. $2^{a}$ ed. São Paulo: Santos; 2011:17-28

39 Fowler CG. Eletrophisiological evidence for the souces of the masking level difference. J Speech Lang Hear Res 2017;60(08): 2364-2374. Doi: 10.1044/2017_JSLHR-H-16-0251

40 Starr A, Hamilton AE. Correlation between confirmed sites of neurological lesions and abnormalities of far-field auditory brainstem responses. Electroencephalogr Clin Neurophysiol 1976;41 (06):595-608

41 Hall JW. Handbook of auditory evoked responses. Boston: Allyn \& Bacon; 2006

42 Song JH, Banai K, Russo NM, Kraus N. On the relationship between speech- and nonspeech-evoked auditory brainstem responses. Audiol Neurotol 2006;11(04):233-241 